\section{Былое и думы. \\ ч. II. Экономические дискуссии времен перестройки}

В.И. КлистоРИн, доктор экономических наук, Институт экономики и организации промышленного производства СО РАН, Новосибирск. E-mail: klistorin@ieie.nsc.ru

Рассмотрены основные экономические дискуссии в СССР в периоды «застоя» (1970-1984 гг.) и «перестройки» (1985-1990 гг.). Показано, что предмет и тематика обсуждаемых научных и практических проблем диссонировали с реальными социально-экономическими процессами, происходящими в стране. Описаны некоторые причины этого явления. Предмет и методы ведения дискуссий, состав их участников резко поменялись в эпоху гласности. Позиции различных сторон кардинально разошлись. Но эти дискуссии послужили скорее дезориентации властей и общественности, нежели помогли поиску решения проблем реформирования экономики и общества.

Ключевые слова: застой, гласность, перестройка, социализм, хозяйственный механизм, рыночные реформы, приватизация

В первой части статьи* был представлен краткий обзор экономических дискуссий на разных этапах социалистического развития страны. Рассматривались предмет и тематика, методы и позиции участников обсуждений. Мы пытались понять, почему выдвигались те или иные вопросы, каковы были итоги для науки, практики и общества в целом. Ранее обзоры эволюции отечественной экономической науки были выполнены разными авторами, некоторые из них упомянуты в первой части статьи. Профессор Ю.Я. Ольсевич предложил рассматривать в качестве главного фактора формирования парадигмы и тематики исследований не столько проблемы развития социалистического хозяйства, сколько запросы правящей бюрократии [1. С. 535 539, 554-591]. В своей работе он делает важный вывод о том, что в 1970-х - 1980-х годах произошел отказ от идеи строительства коммунизма, равно как и от различных вариантов рыночного социализма, в пользу неограниченного во времени этапа «совершенствования социализма». В теории на авансцену выходят концепции «развитого социализма», с одной стороны,

${ }^{*}$ Клисторин В. И. Былое и думы. Ч. І. Какв России ищут ответынавызовы в смутные времена // ЭКО. - 2016. - № 1. - С. 93-103. и «системы оптимального функционирования экономики» (СОФЭ) - с другой [1. С. 538].

\section{Экономические дискуссии в эпоху застоя}

Период 1970-е - начало 1980-х годов получил название «эпохи застоя». Но любое лапидарное определение более или менее продолжительного периода жизни страны всегда будет неточным. Это было время достаточно серьезных и крупных событий и решений. Строились БАМ, КАМАЗ и Атоммаш, КАТЭК, Западно-Сибирский нефтегазовый комплекс и магистральные нефте- и газопроводы, ГЭС на Енисее и Ангаре (Саяно-Шушенская, Усть-Илимская, Богучанская), города и комплексы предприятий при них, была принята программа развития Нечерноземья Перечень крупнейших проектов можно продолжить. Бурно рос и качественно менялся военно-промышленный комплекс.

Не менее активно проявлял себя СССР и на международной арене. Помимо вьетнамской и афганской, страна была вовлечена и в другие войны и конфликты: в Эфиопии, Анголе, Мозамбике, на Ближнем Востоке, в Азии и Латинской Америке. Перечень можно продолжить

Не наблюдалось застоя и в различных областях интеллектуальной и культурной жизни страны. Можно долго перечислять фамилии писателей, поэтов, режиссеров и артистов, художников, инженеров и ученых, их достижения и вклад в соответствующие отрасли интеллектуальной деятельности.

Тогда почему же застой? Становилось очевидным, что, несмотря на все свои достижения, централизованная плановая советская экономика постепенно проигрывает соревнование с децентрализованной рыночной экономикой условного Запада. Темпы прироста экономики СССР вроде бы вдвое превышали показатели США, но разрыв в масштабах экономик и производительности труда не уменьшался. Особенно впечатляла разница в качестве продукции.

Стали явными проблемы в инновационном развитии страны. Научные открытия годами не превращались в технологии, а последние не находили спроса со стороны промышленности и других отраслей. Появился термин «внедрение», фактически означавший систему принуждения к технологическому обновлению. В полувоенных структурах, вроде отраслей «девятки», 
внедрение шло лучше, но в остальных тормозилось. Одновременно функционировала целая индустрия промышленного шпионажа и копирования зарубежных технологий.

Плохо обстояло дело с эффективностью использования ресурсов. По показателям производительности труда, материалоемкости и эффективности инвестиций СССР отставал от промышленно развитых стран. Экономика была тяжелой и неповоротливой. Это означало экстенсивный тип развития, который неизбежно приводил к стагнации по мере исчерпания ресурсов. Если в довоенные и первые послевоенные годы промышленность в целом, и ВПК в особенности, были реципиентами, а донорами были аграрный сектор и природно-ресурсный потенциал, то в 1970-е уже и аграрный сектор стал реципиентом. Вспомним ежегодные поездки на сельскохозяйственные работы студентов и сотрудников большинства предприятий и организаций. СССР превращался в сырьевую державу, зависимую от конъюнктуры мировых рынков.

Неизбежное торможение экономического развития наслаивалось на быстрое снижение вертикальной социальной мобильности. Был популярен такой анекдот: «Может ли сын генерала стать маршалом? Нет, поскольку у маршала тоже есть сын». Общество все более стратифицировалось, и каждая из социальных и профессиональных групп постепенно «закукливалась». То же самое относилось и к сфере управления, партийным органам и силовым ведомствам. Обычными стали династические браки, наследование должностей и званий в науке и образовании, промышленности, в партийных и советских органах, министерствах и ведомствах. Окончательно оформилась советская элита на месте старой номенклатуры. Эта элита воспроизводилась в автономном режиме, в отличие от номенклатуры, которая формировалась и обновлялась под жестким партийным контролем. Комсомол и высшее образование перестали быть гарантами карьеры.

Свертывание реформ, связываемых с именем А.Н. Косыгина, из-за страха потери управляемости в стране и превращения рыночного социализма в либерализацию политической жизни по чехословацкому образцу породили уныние у части интеллигенции, включая экономистов. Накапливалась усталость от того, что теоретические обсуждения и практические рекомендации ходили по кругу, что резко контрастировало с явным прогрессом в других науках и с достижениями зарубежного обществоведения.

Все это дополнялось ощущением того, что страна живет в атмосфере лжи. Трудно верить официальной статистике, речам руководителей партии и правительства, СМИ, когда из года в год читаешь и слышишь победные реляции, а личные ощущения и разговоры на кухне свидетельствуют о другом Фальшивым было, казалось, всё: от всенародного обсуждения основных направлений развития народного хозяйства СССР на очередную пятилетку, собраний и конференций, до выборов любого уровня.

Директора уже рассматривали предприятия как свою собственность и обустраивали для себя автономное пространство строили жилье и базы отдыха, детские сады и спортивные площадки, подсобные хозяйства и цехи, помогали, а фактически содержали местные советы, парткомы и профкомы. В некоторых сельских районах фактически уже не было и советской власти, поскольку все, от милиционеров до суда, содержались на средства совхозов.

Что касается научных дискуссий, то они концентрировались, во-первых, вокруг технологии планирования, когда правильные методы агрегации и дезагрегации показателей позволяют согласовывать оптимальные планы на уровне народного хозяйства отраслей, экономических районов, а их, в свою очередь, - с планами краев, областей, городов и предприятий. Эта деятельность стимулировалась разработкой и внедрением АСУ.

Параллельно шли споры о том, какие показатели или системы показателей в наибольшей степени отражают цели социалистического воспроизводства. Что лучше: объем товарной или реализованной, чистой или нормативно-чистой продукции и т. д. Точно такая же дискуссия велась об экономической сущности и практическом использовании норматива эффективности капитальных вложений - должен ли быть этот норматив единым для народного хозяйства или дифференцированным для различных отраслей, регионов или типов проектов, какова его связь с ограниченностью фонда капитальных вложений, темпами роста экономики, ставкой платы за фонды или банковским процентом и т. д. 
Эти дискуссии носили схоластический характер хотя бы в силу того, что ценообразование в СССР оставалось плановым и централизованным. Для обоснования эффективности некоторых проектов проще было доказать их народнохозяйственную и социальную эффективность и исходя из этого обосновать необходимость корректировки цен на новую продукцию, нежели привести калькуляцию на базе стандартных нормативов.

В основе цен лежали так называемые общественно необходимые затраты и норматив рентабельности, что почти автоматически вело к их установлению на уровне среднеотраслевых. Вне зависимости от того, какой концепции придерживались экономисты (цены производства, стоимостной, цен оптимального плана (ООО-оценок) или равновесных), результат был один и тот же - затратное ценообразование и рост издержек на лоббирование и согласование.

Следующее направление исследований можно определить как дискуссии вокруг оценки эффективности капитальных вложений и новой техники, территориальной организации хозяйства, инфраструктурных проектов и освоения новых территорий. Потом эта тематика стала включать и проблемы реконструкции промышленных узлов и районов. Споры шли вокруг сочетания отраслевого и территориального принципов управления народным хозяйством.

Большое развитие получили комплексные региональные исследования на стыке экономики, демографии, социологии и географии.

Особым направлением экономических исследований следует считать оценку природных ресурсов для выбора вариантов их хозяйственного освоения, обоснования платежей за использование природных ресурсов, определение «оптимального» уровня загрязнения окружающей среды в целях недопущения ее деградации. Особо следует выделить работы по экономической оценке земель, в том числе и городских, которые базировались на марксистской теории ренты и, следовательно, приводили к обсуждению так называемого противоречия между первым и третьим томами «Капитала».

Все эти проблемы, при всей их важности, имели слабое отношение к коренным проблемам развития советского общества. Преобладал технократический подход к их решению. Считалось, что при достаточном обеспечении вычислительными мощностями и памятью ЭВМ, должном финансировании и организации контроля за полнотой и качеством информации экономика действительно достигнет оптимального состояния и встанет на траекторию устойчивого развития.

Эмпирическим исследованиям придавалось сравнительно небольшое значение, поскольку их результаты применялись скорее для подтверждения теоретических выводов. Используемые методы экономического анализа в большинстве своем были примитивными, застрявшими на уровне начала - первой половины XX века. Для обоснования решений мало помогали экономические эксперименты, поскольку они часто проводились в несопоставимых условиях.

Специалисты тех институтов, которые выезжали в экономические и социологические экспедиции, лучше знали реальное положение дел в экономике, но не все материалы полевых исследований могли публиковаться, многие из них были засекречены. Итог проведенной работы подвел Ю. В. Андропов, который сказал, что мы плохо знаем общество, в котором живем и работаем.

\section{Дискуссии в период перестройки и гласности}

Приход к власти М.С. Горбачева не обещал ничего принципиально нового, кроме обновления состава и омоложения высшего партийного руководства и правительственного аппарата. Но новому руководству нужны новые лозунги и идеи. Такими лозунгами стали антиалкогольная кампания и программа ускорения. Стагнация в экономике объяснялась упадком морально-нравственных ценностей и трудовой дисциплины на фоне высокого потребления алкоголя и плохого использования ресурсов из-за недостатков в работе ряда министерств. Первая проблема должна была быть решена запретами и уничтожением сырьевой базы производства алкоголя, вторая - укрупнением министерств и ведомств и более жестким контролем за их работой. Предполагалось, что это позволит более эффективно использовать ресурсы и поднять уровень жизни населения.

После провозглашения политики гласности освобождение некоторых диссидентов, перевод ряда книг из спецхранов в открытые фонды и тому подобные практические шаги привели к взрыву дискуссий и резкой смене их тематики. 
Прежде всего, ревизии подверглись оценки результатов социалистического строительства, достижения и невозвратные потери эпохи И.В. Сталина и успехи СССР в соревновании двух систем. Интересно, что обсуждение этих вопросов шло не столько в экономических, сколько в литературных журналах, вроде «Нового мира», и публицистических изданиях, от «ЭКО» до журналов «Огонек» и «Век XX и мир».

Необходимо выделить статьи В. Селюнина и Г. Ханина «Лукавые цифры» [2], Л. Попковой (Л.И. Пияшевой) «Где пышнее пироги?» [3] и ответ О. Лациса на статью Л. Пияшевой [4], опубликованные в «Новом мире» в 1987 г.

В первой статье представлена жесткая критика советской статистики, которая, манипулируя ценами, систематически завышала результаты экономического развития страны. Это приводило к дезориентации всех субъектов, включая властные органы. Отдавая приоритет оценкам в натуральных показателях, авторы указывают, что «денежные измерители исправно служат там, где деньги играют активную роль в экономике, являются важнейшим инструментом хозяйственного механизма. При чрезмерной централизации, при тотальном планировании и директивном распределении практически всех ресурсов деньги своих функций не выполняют» [2. С. 40]. То есть, присутствует намек, что дело даже не в статистике, а во всей политико-экономической системе реального социализма.

Еще дальше в своих рассуждениях пошла Л. Пияшева, писавшая фактически о том, что план и рынок несовместимы, и рассуждения о рыночном социализме в лучшем случае есть заблуждение и благоглупость. О. Лацис, тонко чувствовавший опасность, ответил, что советский вариант социализма не следует воспринимать как приговор системе, социализм имеет резервы для своего улучшения.

Эти работы породили бесчисленное количество публикаций, в которых, наряду с развенчанием культа личности и критикой достижений реального социализма, предлагались практические рецепты реформирования экономики и общества. Редакции журналов были завалены статьями на эти темы. Кое-где такие работы получили название «доцентских писем», которые надлежало выбрасывать в корзину.
Здесь следует сделать отступление по поводу экономического образования в СССР. Изучение курсов политической экономии капитализма и социализма давало отрывочные, искаженные и в большинстве случаев неверные представления о функционировании этих политико-экономических систем. Работы К. Маркса, Ф. Энгельса, В.И. Ленина были разобраны на цитаты, которые воспринимались как догматы, вне исторического контекста целей и замысла произведений. Ссылки на классиков и решения съездов КПСС были главным аргументом в дискуссиях. Поэтому представление о том, как функционирует институциональная система той или иной страны, включая собственную, было крайне поверхностным. Эти знания были дополнены моделями из зарубежных учебников и переводных книг, которые ранее критиковались отечественными специалистами.

Долгие годы изучения должного вместо реальности не могли не повлиять на квалификацию ученых и мировосприятие общественности. Все это сказывалось на качестве анализа, воспитывало некритическое отношение к научным текстам, публицистике и реальной жизни. Все мы были догматиками, хотя и в разной степени, что не мешало ожесточенной полемике. С этой точки зрения интересна статья В.Н. Богачева, в которой он разбирает заблуждения и упрощенность рекомендаций своих коллег [5].

Предложения по реформированию экономики часто были утопичными и сводились к рекомендациям «от противного», т. е. если при социализме цены директивные, то при капитализме - свободные, если при социализме преследуются спекуляция и частная инициатива, то при капитализме они ничем не стеснены и т. д. Или, наоборот, предлагался возврат к «очищенному социализму», который возможен, если набрать две тысячи грамотных и честных специалистов, создать эффективную систему контроля, убрать привилегии номенклатуры и установить научно обоснованные цены.

Меньшинство призывало вернуться к ленинским принципам и строительству социализма по Марксу, большинство уже не ссылалось на авторитеты и предлагало различные варианты реформ для того, чтобы двинуться в сторону Швеции, Польши, Чили или в каком-то ином направлении, но только подальше от реального социализма. 
Обзор экономических дискуссий времен перестройки выполнил Г.И. Ханин [6. С. 4-37]. Он выделил четыре группы участников дискуссии и, соответственно, четыре концепции реформ:

- модифицированная командная система;

- концепция двухсекторной экономики;

- постепенный переход к рыночной экономике;

- радикальная рыночная реформа.

Сами наименования групп дают представление об идеологических позициях и предложениях авторов. Г.И. Ханин пытался соблюсти объективность в своем анализе, но видно, что он симпатизирует сторонникам мобилизационного пути реформирования экономики, хотя и отмечает их слабость в обосновании позитивных рекомендаций [6. С. 19]. Он отдает должное авторам, особенно зарубежным, предлагающим медленный переход к рыночной экономике. Следует отметить, что иностранные специалисты, изучавшие экономику СССР, гораздо большее внимание уделяли анализу экономических процессов и использованию количественных методов в отличие от отечественных авторов, предпочитавших качественный анализ, разбор кейсов и уделявших большое внимание идеологическим и политическим факторам и ограничениям (см., например [7]).

Более краткий, но при этом более емкий анализ идеологических и политико-экономических воззрений участников дискуссии представил Г.С. Кордонский [8], который попытался выявить возможные коалиции групп со схожими интересами и высказал предположение о вероятном союзе бюрократии и сторонников радикальных реформ.

Самым важным в этих дискуссиях было снятие табу на обсуждение реальных проблем экономики и общества и осознание того, что экономические проблемы страны имеют политические корни. С точки зрения качества научной проработки и обоснованности выводов и рекомендаций сторонники градуализма были много выше своих оппонентов как слева, так и справа. Но нарастающий политический и экономический кризис резко сужал поле выбора действий. Элиты и общество быстро радикализировались, что и привело к последующим событиям.

Это наглядно видно при сравнении содержания двух сборников статей, выпущенных под общей шапкой «Социализм. Гласность. Перестройка». Если первый, вышедший в 1988 г., назывался
«Постижение» [9] и включал преимущественно аналитические статьи, то второй, «Погружение в трясину» [10], опубликованный в 1991 г., уже был откровенно публицистическим, а его содержание можно свести к названию фильма С. Говорухина «Так жить нельзя», вышедшего на экраны в то же время.

Рабочая группа под руководством академика С. С. Шаталина разработала программу под названием «Переход к рынку» [11] в которой был представлен квалифицированный анализ основных тенденций и проблем развития страны, перечислены сценарии и варианты действий: постепенные преобразования, откат и радикальная экономическая реформа [11. С. 23-24]. Последний сценарий, несмотря на название, предполагал последовательность и градуализм.

Дальнейшая полемика привела лишь к потере времени, и программа не была реализована. Но она сыграла огромную роль в смене дискурса. На первый план вышли проблемы состава бюджетных расходов, структурный маневр в инвестиционной сфере, конверсия, преобразования финансовой системы, приватизация, поддержка предпринимательства, создание рыночной инфраструктуры и другие.

Поскольку многие проблемы были слабо освещены в отечественной научной литературе или просто игнорировались, возникли претензии к экономической теории [12].

Вместе с тем решения, принимаемые руководством страны исходя из тактических соображений и на основе множества компромиссов, каждое из которых имело рациональное обоснование, приводили в целом к быстрому ухудшению ситуации. Нормативные акты о деятельности предприятий, государственном заказе, кооперации, арендных отношениях, совместных предприятиях и т. д. привели к бесконтрольным процессам приватизации оборотных средств предприятий, роста денежного навеса и дефицита товаров, увеличения внешнего долга страны, развития частного сектора, в основном за счет спекуляции.

\section{Заключение}

Бурные экономические дискуссии происходили в разные периоды жизни нашей страны. Общим было то, что структура и темпы развития экономики признавались неудовлетворительными, система и механизмы управления народным хозяйством 
вызывали недовольство как сверху, так и снизу. Попытки решать проблемы по мере их выявления приводили к неожиданным и нежелательным последствиям.

С приходом к власти М.С. Горбачева в обстановке гласности резко изменились тематика и тон дискуссий. Поставив под сомнение достижения и преимущества реального социализма, участники обсуждений увязали решение экономических проблем с политическими вопросами.

Но, как и ранее в отечественной истории, экономические дискуссии оказывали крайне незначительное воздействие на решения органов власти. Последние скорее использовали риторику, терминологию и аргументы ученых и специалистов для обоснования тех решений, которые им казались наиболее удобными с тактической точки зрения. С другой стороны, многие участники дискуссий прекрасно понимали зигзаги политического курса и подстраивались под него.

Экономические дискуссии времен перестройки выявили, что общедоступная аналитика оказалась на крайне низком уровне, ученые изучали не то и не так и фактически обманывали общественность, власти и самих себя. Как бывает всегда в периоды экономической и социальной турбулентности, происходило развенчание авторитетов, и на сцену выходили новые, среди которых было много жуликов и демагогов.

По мере ухудшения состояния экономики и усиления недовольства различных групп населения росла поляризация точек зрения по поводу причин кризиса и направлений дальнейшего развития. Власти же пытались балансировать между ними, что приводило к потере времени и сужению доступных альтернатив.

Как мы теперь понимаем, под аккомпанемент дискуссий о методологии планирования и прогнозирования, пределах хозяйственной самостоятельности предприятий в период «застоя» страна шла к экономическому и политическому кризису. Точно так же на фоне обсуждения альтернативных направлений и темпов экономических преобразований, различных программ перехода к рынку в СССР создавались первые банки и биржи, появились десятки и, возможно, сотни тысяч частных предприятий, на которых работали сотни тысяч, если не миллионы человек. В условиях правового вакуума появились первые миллионеры, шла деградация государственного аппарата, набирали силу коррупция и организованная преступность. Наступала новая эпоха, которая породила иную систему отношений, иную социальную организацию общества и иные дискуссии.

\section{Литература}

1. История экономических учений: (современный этап). Учебник / Под общ. ред. А. Г. Худокормова. - М.: ИНФРА-М, 1999. - 733 с.

2. Ханин Г.И. Экономика и общество России: ретроспектива и перспектива: избр. тр. в 2 т. Т. 1. - Новосибирск: Изд-во СибАГС, 2015. $384 \mathrm{C}$.

3. Попкова Л. Где пышнее пироги? // Новый мир. - 1987. - № 5. URL: http://www.agitclub.ru/gorby/glasnost/processpopkova.htm

4. Лацис О. Зачем же под руку толкать? // Новый мир. - 1987. - № 7. URL: http://www.agitclub.ru/gorby/glasnost/processlazis.htm

5. Богачёв В. Н. Освоить бы накопленное // ЭКО. - 1987. - № 6. C. $119-133$.

6. Ханин Г. И. Экономика и общество России: ретроспектива и перспектива: избр. тр. в 2 т. Т. 2. - Новосибирск: Изд-во СибАГС, 2015. $371 \mathrm{c}$

7. Хьютт Э. Экономические реформы в СССР. 1985-1987 гг. // ЭКО. 1989. - № 6. - С. 37-48.

8. Кордонский С.Г. Три мифа и четыре кита перестройки // Век XX и мир. - 1990. - № 4. - С. 19-26.

9. Постижение: Социология. Социальная политика. Экономическая реформа. /Ред.-сост. Ф. М. Бородкин, Л.Я. Косалс, Р. В. Рывкина. - М. Прогресс, 1988. - 332 с.

10. Погружение в трясину (Анатомия застоя) /Сост. и общ. ред Т. А. Ноткиной. - М.: Прогресс, 1991. - 704 с.

11. Шаталин С.С., Петраков Н.Я., Явлинский Г.А. и др. Переход к рынку. Концепция и Программа. - М.: «Архангельское», 1990. -239 с. 12. Майбурд Е. М. Снимем шляпу Карла Маркса с нашей головы // ЭКО. - 1991. - № 8. - С. 209-213. 